\title{
STUDY OF (PB, BA) - CRT GLASS WASTE BEHAVIOUR AS A PARTIAL AGGREGATE REPLACEMENT IN CEMENT MORTARS
}

\author{
LILIANA HORNEA ${ }^{a}$, MARIA GOREA ${ }^{\mathrm{b}}$, NICOLAE HAR ${ }^{\mathrm{a} *}$
}

\begin{abstract}
This study investigates the usability of the cathode ray tube (CRT) glass waste in a binder system. The raw materials - glass waste, river sand and cement were characterised. CRT waste was added in the amount of 30, 40 to 50 weight percent, as replacement for river sand. Glass chemical composition shows a high content in lead and alkaline oxides. Mortar prisms were prepared and kept under humid conditions. The mechanical properties were studied after 7, 28 and 90 days respectively. SEM with additional EDS was used in order to investigate the microstructure of the samples. All the samples containing glass waste achieved higher compressive strength than the control mortar. After 14, 28 and 42 days of maintaining the mortar in water no evidence of $\mathrm{Pb}$ was detected in the solutions.
\end{abstract}

Key words: cement, mortar, CRT glass waste, compressive strength

\section{INTRODUCTION}

It is well known that the process of recycling represents the trend of the modern world. This process is closely related to the quantity of products removed from the market [1-5]. The electronic and electro-technical fields go through changes every day since the beginning of rapid technological achievements [6]. Good examples are computer monitors and TV sets that are composed of cathode ray tube (CRT) glass. If 25 years ago, these products were recycled, being used to create new devices, at present, their market demand is non-existent, given the superiority of liquid crystal display (LCD) and light emitting diode (LED) technology [7].

\footnotetext{
a Babeş-Bolyai University, Faculty of Biology and Geology, Kogălniceanu str., 1, RO-400084 Cluj-Napoca, Romania.E-mail: liliana.hornea@gmail.com; nicolae.har@bioge.ubbcluj.ro

b Babeş-Bolyai University, Faculty of Chemistry and Chemical Engineering, 11 Arany Janos str., RO- 400028, Cluj-Napoca, Romania, mgorea@chem.ubbcluj.ro

*Corresponding author: nicolae.har@bioge.ubbcluj.ro
} 
Introduction of glass waste as aggregate replacement in mortar and concrete has been studied for a long time. In the last 10 years this area has been intensely discussed by researchers due to high costs required for disposal but especially as a consequence of the new environmental regulations [8-11]. Electrical and electronic waste equipment involves serious environmental problems both due to their growing volume as well as to their toxicity caused by their content in $\mathrm{Pb}, \mathrm{Mn}, \mathrm{Zn}, \mathrm{Sn}$, Co etc., respectively. Eliminating CRT glass has become a worldwide environmental problem due to its high content in lead [12]. There are now plenty of ways to recycle this waste. One of them is to use it in the manufacturing of other monitors but the method becomes useless due to the low demand of CRT monitors [13]. Another method involve using these materials as flux in glass and ceramics industry [14-17]. These technologies limit the content of toxic oxides, mainly $\mathrm{PbO}$. As a result, a separation of glass waste containing lead is required. This increases the price of the final product. Waste shredding and washing with acid to remove lead is also a complex process [4, 18]. Castro and Brito [19] review the main attempts regarding the feasibility of introducing glass waste in concrete as an aggregate. Promising results on lead immobilization from waste in a binder matrix (Portland cement, mixed silicate binders and other derived blender cements) would justify their use as a partial replacement of mineral aggregates in certain types of concrete [20].

The main aim of this study is to characterize the composition of CRT glass and to prepare the cement mortars in which the natural sand is partially replaced by these wastes. Also the microstructure characteristics correlated with the mechanical properties of hardened mortar are highlighted. Capacity of lead immobilization in the binder system is also studied.

\section{RESULTS AND DISCUSSION}

\section{Characterization of raw materials}

\section{CRT glass waste aspect}

Cathode ray tube glass waste used in this study represents a mix of funnel and screen glass obtained by the shredding of computer monitors. The computer monitors were scrapped; glass components were separated from the metal and plastic parts, then crushed and finally sieved below 4.00 $\mathrm{mm}$ particle size. The glass waste without any further chemical treatment was used. Particle size of river sand is in the range of 0 to $4.00 \mathrm{~mm}$.

Macroscopic and microscopic aspect of the CRT glass waste is highlighted in Figure 1. The colour of waste is light grey. After the crushing process, the SEM image highlights angular fragments of glass, isometric or elongated in shape, with different sizes up to $4.00 \mathrm{~mm}$. 

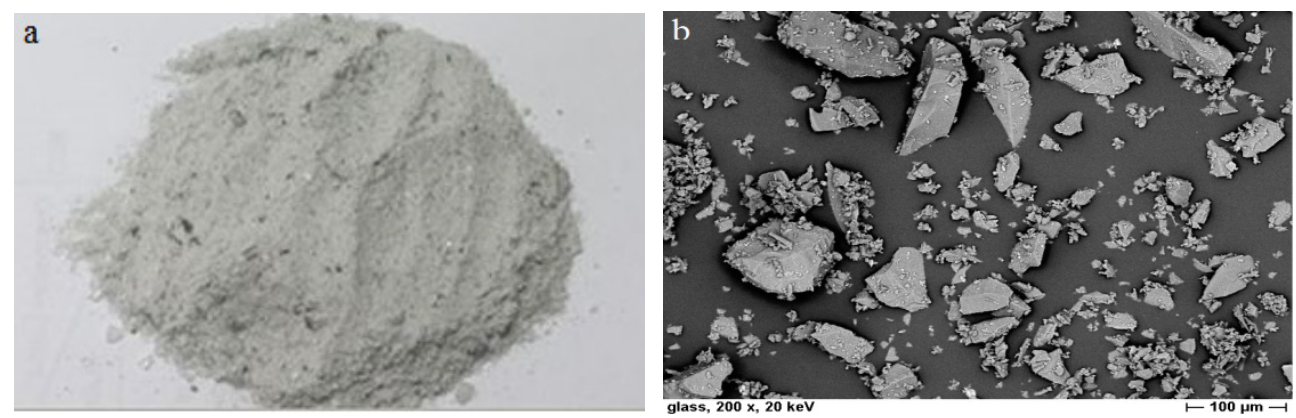

Figure 1. CRT glass waste with size less than $4 \mathrm{~mm}$ : a - macroscopic aspect; b - SEM image

\section{Physical-chemical characterisation}

The traditional river sand for mortar contains a high amount of silicon oxides besides small quantities of aluminium, calcium and alkaline oxides, respectively. The silicon oxide content is lower in CRT glass wastes than in river sand, about $46 \mathrm{wt} \%$. The content of both fluxes oxides and earth and alkaline oxides, respectively is high and lead oxide is also present in high quantity, about $25 \mathrm{wt} \%$.

The CRT glass composition is rich in lead oxide (25 wt \%) which makes this waste difficult to store; hazardous oxides as $\mathrm{BaO}(2.23 \mathrm{wt} \%)$ and $\mathrm{SrO}(2,4 \mathrm{wt} \%)$ are also present. A high content of alkali and alkali-earth oxides $\mathrm{Na}_{2} \mathrm{O}, \mathrm{K}_{2} \mathrm{O}, \mathrm{MgO}$, and $\mathrm{CaO}$ is observed. The sand contains a high amount of silica, about $89 \mathrm{wt} \%$ and aluminium oxide (3.95 wt\%) and, in small proportions, alkali and alkali-earth oxides.

As expected, the glass waste shows a slow water absorption value of $0.04 \mathrm{wt} \%$, smaller as compared with the sand, which is $1.93 \mathrm{wt} \%$. Due to its vitreous texture, glass adsorbs less water than the other aggregate. This fact leads to a higher water amount in the mortar mixture, which involves a better workability.

As compared with sand density $\left(2620 \mathrm{~kg} / \mathrm{m}^{3}\right)$, CRT glass has a higher density $\left(3020 \mathrm{~kg} / \mathrm{m}^{3}\right)$, due to its content in heavy metal oxides $\mathrm{BaO}$, $\mathrm{SrO}$ and $\mathrm{PbO}$. This value is closed to the cement powder density (3150 $\mathrm{kg} / \mathrm{m}^{3}$ ), providing a good blending of raw materials and avoiding aggregates segregation.

Regarding the size distribution of aggregates there are no relevant differences between river sand and CRT glass waste. Therefore, the mortar compactness is expected to be close for control and CRT studied samples.

The physical-chemical characteristics of materials are presented in Tables 1 and 2. 
Table1. Physical-chemical characteristics of raw materials

\begin{tabular}{|c|c|c|c|}
\hline Material/oxide & $\begin{array}{c}\text { Portland Cement } \\
{[\mathrm{wt} \%]}\end{array}$ & $\begin{array}{c}\text { CRT glass waste } \\
{[\mathrm{wt} \%]}\end{array}$ & $\begin{array}{c}\text { Traditional river } \\
\text { sand [wt\%] }\end{array}$ \\
\hline $\mathrm{SiO}_{2}$ & 20.39 & 46.10 & 88.97 \\
\hline $\mathrm{Al}_{2} \mathrm{O}_{3}$ & 4.71 & 3.26 & 3.95 \\
\hline $\mathrm{Fe}_{2} \mathrm{O}_{3}$ & 3.91 & 0.13 & 0.53 \\
\hline $\mathrm{CaO}$ & 61.62 & 3.41 & 2.00 \\
\hline $\mathrm{MgO}$ & 1.11 & 1.71 & 1.00 \\
\hline $\mathrm{Na}_{2} \mathrm{O}$ & 0.21 & 6.24 & 1.05 \\
\hline $\mathrm{K}_{2} \mathrm{O}$ & 0.72 & 7.40 & 1.26 \\
\hline $\mathrm{TiO}_{2}$ & & 0.12 & \\
\hline $\mathrm{SrO}_{\mathrm{ZrO}}$ & & 2.40 & \\
\hline $\mathrm{BaO}$ & & 0.22 & \\
\hline $\mathrm{PbO}$ & & 2.23 & \\
\hline $\mathrm{SO}{ }_{3}$ & & 25.00 & \\
\hline $\mathrm{Cl}$ & 2.74 & & \\
\hline $\mathrm{LOI}^{-}$ & 0.0049 & & \\
\hline Physical Properties & & 0.72 & 0.62 \\
\hline Density $\left[\mathrm{kg} / \mathrm{m}^{3}\right]$ & & & \\
\hline Water absorption [wt\%] & & 3020 & \\
\hline \multicolumn{2}{|l|}{} & 0.14 & \\
\hline
\end{tabular}

The different aggregates density in the cement mortar has to be close to each other and to the binder density. The CRT glass waste and river sand have an adequate density to avoid the aggregates sedimentation during the mixing. The water absorption of CRT glass waste is lower than of the river sand, so the mixture workability is not influenced.

\section{Aggregate sizes}

The size distribution of the aggregates is presented in Table 2. The size of both aggregates are similar. This fact involves a good homogenisation of aggregate fragments and of mortar mixtures.

Table 2. Aggregates sizes

\begin{tabular}{|l|l|l|l|l|l|l|l|l|}
\hline Aggregate/Sieve size & {$[\mathrm{mm}]$} & 4.00 & 3.15 & 2.00 & 1.40 & 1.00 & 0.71 & 0.50 \\
\hline CRT glass waste & {$[\mathrm{wt} \%]$} & 100.00 & 93.50 & 87.17 & 76.34 & 64.34 & 53.67 & 44.00 \\
\hline Traditional river sand & {$[\mathrm{wt} \%]$} & 100.00 & 95.90 & 81.20 & 72.70 & 62.60 & 56.00 & 45.30 \\
\hline
\end{tabular}




\section{Alkali solubility of glass waste}

The $\mathrm{pH}$ measurements show that the $\mathrm{pH}$ value of the glass solution has slight variations in the first two hours. In this time interval the highest value is 9.68 (Figure 2,a).

Following the $\mathrm{pH}$ evolution, in the $3^{\text {rd }}$ day, the $\mathrm{pH}$ value increases to 10.15 then drops to 10.07 . $\mathrm{pH}$ values remain almost constant starting with the $5^{\text {th }}$ day (Figure 2, b). This $\mathrm{pH}$ value is recommended for the cement mortars.

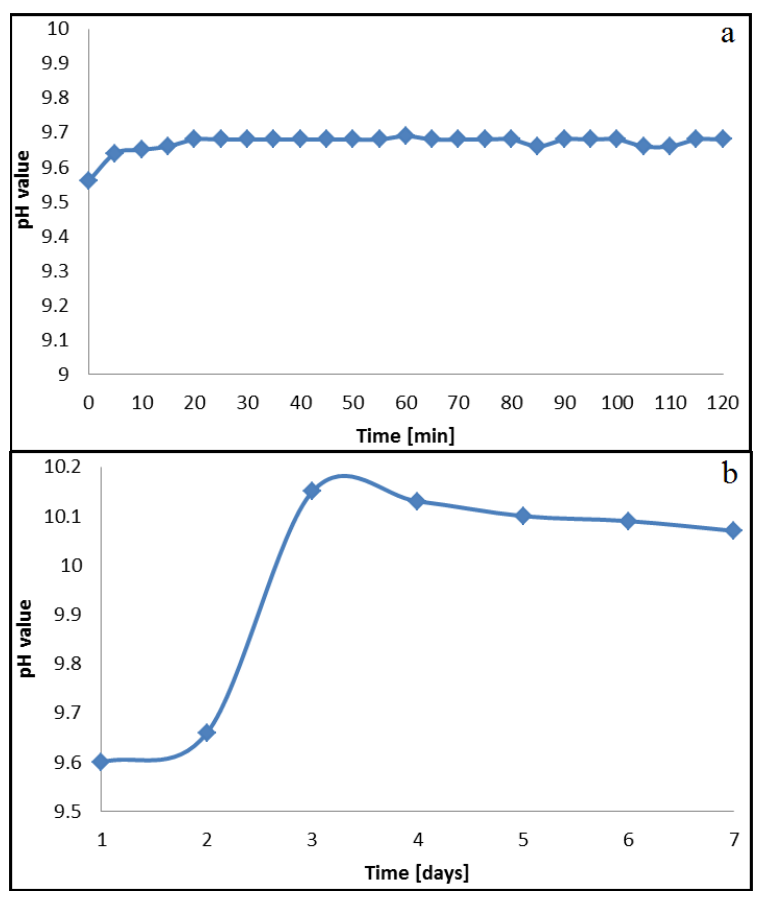

Figure 2. Evolution of $\mathrm{pH}$ solution of CRT glass waste during (a) 2 hours; (b) 7 days

\section{Hydraulic activity of CRT waste}

Hydraulic activity measures the reaction capacity of a substance/ material with calcium hydroxide in the presence of water. The hydraulic activity of CRT glass waste was studied at two different maturation intervals of 8 and 16 days, respectively. Following the processing of the data obtained from solution titration, it can observe that the values of CRT glass hydraulic activity are above the saturation curve of $\mathrm{CaO}$ (Figure 3 ). 


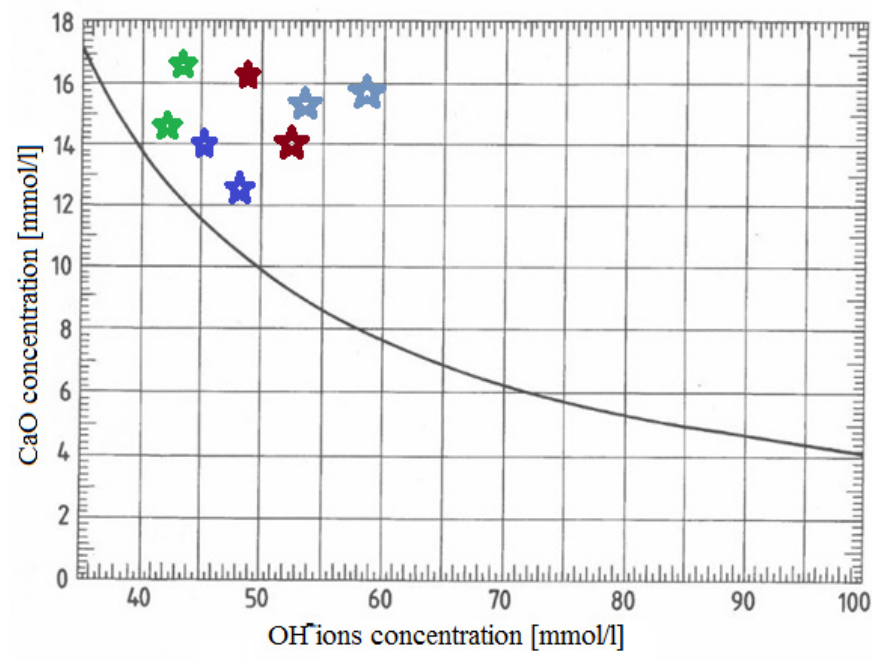

Figure 3. Distribution of sample concentrations on $\mathrm{CaO}$ saturation curve:

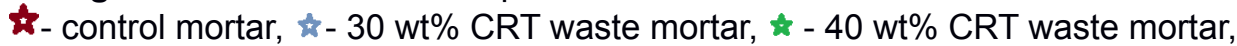
^-50 wt\% CRT waste mortar.

According to the convention regarding the hydraulic behaviour, the points above the saturation curve of $\mathrm{CaO}$ indicate a poor hydraulic activity. This encourages the use of cathode glass waste as aggregate in cement mortars.

\section{Mortar Characterization}

Cement mortars compositions

Four cement mortars compositions were prepared according to Table 3. The control mortar mixture (M1) is free of CRT glass waste, while the other three compositions have the river sand aggregates substituted by CRT glass waste in the proportions of $30 \mathrm{wt} \%, 40 \mathrm{wt} \%$, and $50 \mathrm{wt} \%$ respectively. All the mixtures were prepared with water/cement ratio of 0.5 and with aggregate/cement ratio of 3 .

Table 3. Experimental mortars mixtures

\begin{tabular}{|l|l|l|l|}
\hline Sample / Component [wt\%] & \multirow{2}{*}{ Portland cement } & \multicolumn{2}{|c|}{ Aggregate } \\
\cline { 3 - 4 } & & River sand & CRT glass \\
\hline M1 & 25 & 75.00 & - \\
\hline M2 & 25 & 52.50 & 22.50 \\
\hline M3 & 25 & 45.00 & 30.00 \\
\hline M4 & 25 & 37.50 & 37.50 \\
\hline
\end{tabular}


STUDY OF (PB, BA) - CRT GLASS WASTE BEHAVIOUR AS A PARTIAL AGGREGATE ...

\section{Mineralogical investigations}

The mortar phases are well revealed by BSE images in Figure 4. As expected, grains of quartz (Q), feldspars (Fsp) and glass (G) appear in the cement matrix (M).
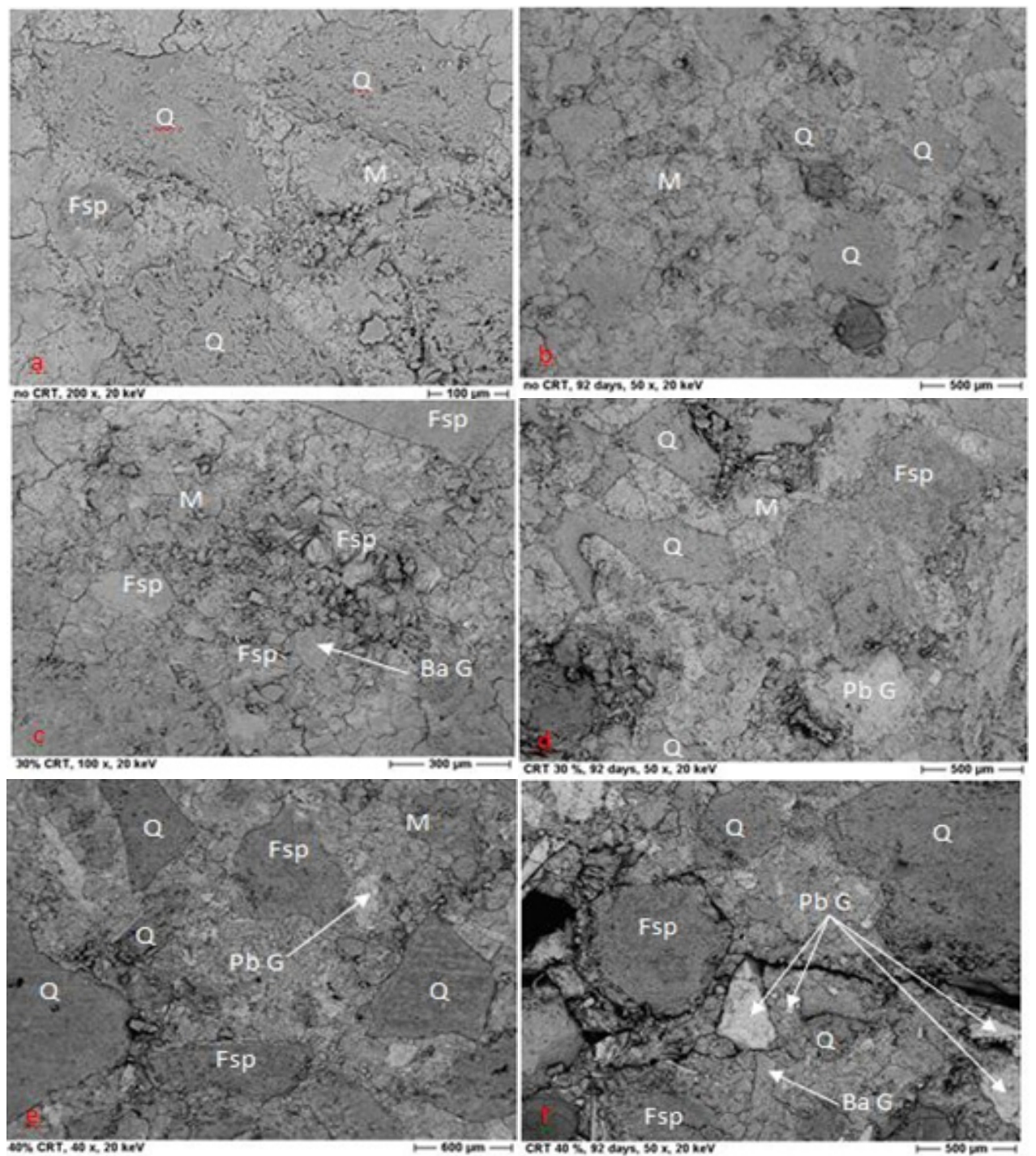

Figure 4. BSE images of mortars: a - control mortar 28 days, b - control mortar 90 days, c - 30\% CRT mortar 28 days, d - 30\% CRT mortar 90 days, e - 40\% CRT mortar 28 days, $f-40 \%$ CRT mortar 90 days (quartz - Q, feldspars -Fsp, lead glass - PbG, barium glass $-\mathrm{BaG}$ and cement matrix $-\mathrm{M}$ ) 
The mortar control sample aspect is illustrated in Figure $4 a$ and b. In each samples grains of quartz and feldspar with specific shapes and sizes from the aggregate in mortars are well observed. As expected, mortar samples are well blended, the aggregate grains are dispersed in the cement matrix and the mortar microstructure is compact. The cracks observed in the samples are the result of the mechanical tests and the dehydration processes which took place during sample preparation.

Quartz grains are bound in a matrix that consists of calcium silicate hydrates, calcium ferrite aluminate hydrates and also magnesium compounds. These components are hydrated and form a homogenous mixture. On the upper side of the sample, the carbonation process is present. Its appearance may have different explanations. It might be that the mortar samples were held in natural atmosphere, so the $\mathrm{CO}_{2}$ could enter through the pores in the mortar structure. There, it would react with the portlandite resulted from calcium oxide hydration and form calcium carbonate - calcite. Another possible explanation could be the presence of limestone as additive in Portland cement type II A-LL.

The 30 wt\% CRT mortar microstructure, in which the CRT glass (BaG - barium glass and PbG - lead glass) has angular shape with sharp edges as a result of the grounding process, is shown in Figure $4 \mathrm{c}$ and $\mathrm{d}$. The same sharp boundaries of glass in the cement matrix can be observed on the 40 wt $\%$ CRT mortar microstructure - Figure $4 e$ and $f$.

The composition of glass waste aggregates of mortar containing 50 wt\% glass (sample M4) was investigated by BSE and EDS (Figure 5). Pieces of glass with high $\mathrm{Pb}$ content (spectrum b) and $\mathrm{Ba}$ content (spectrum a) are revealed.

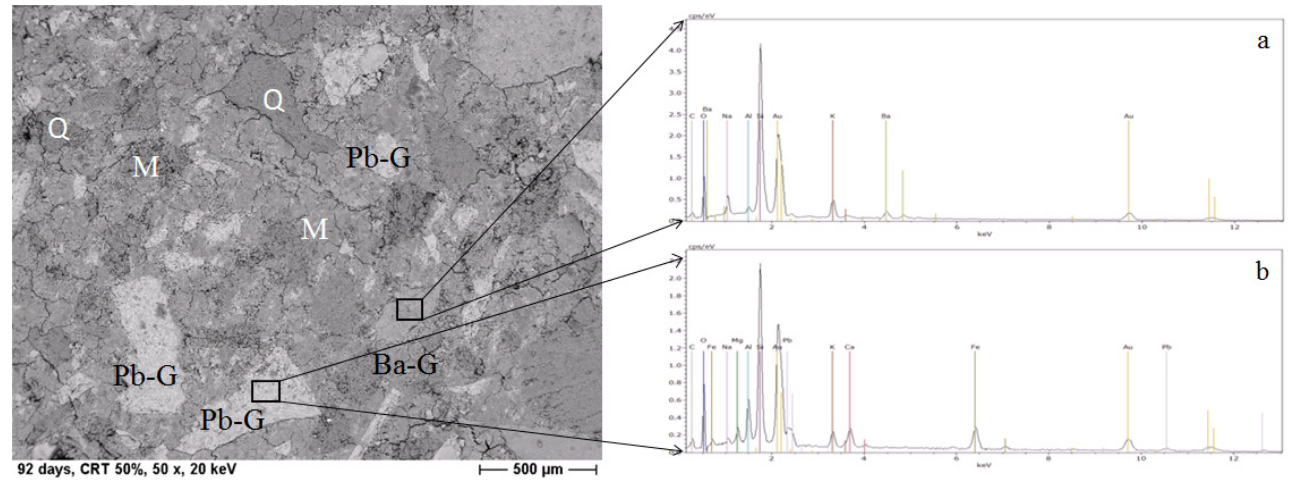

Figure 5. BSE image and EDS spectrum of the $50 \%$ CRT mortar after 90 days 
EDS investigations reveals the same chemical elements found by the chemical analysis. Two types of glass are highlighted: one that contains $\mathrm{Pb}$ and one that is rich in $\mathrm{Ba}$. This fact indicates the different sources of glass: computer pannel for $\mathrm{Ba}$ type and cathode for $\mathrm{Pb}$ type. The occurence of $\mathrm{Pb}$ and $\mathrm{Ba}$ glass pieces in the mixture is rather random, no particular distribution is observed.

\section{Density of the hardened mortar}

The density of studied hardened mortars increases with the increase of CRT glass waste content in mortar compositions. The highest density is reached by the $50 \mathrm{wt} \%$ CRT glass containing mortar $-2286.29 \mathrm{~kg} / \mathrm{m}^{3}$, while the control mortar has the lowest value $-2190.63 \mathrm{~kg} / \mathrm{m}^{3}$ (Figure 6).

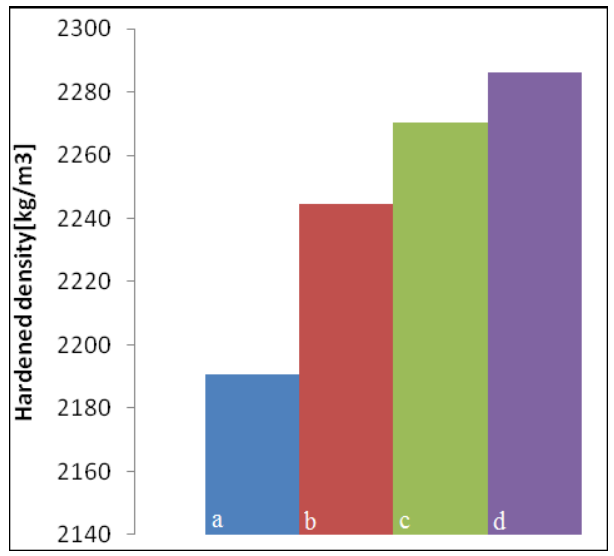

Figure 6. Density variation of studied mortars: a - control mortar,

b - 30 wt $\%$ CRT mortar, c - 40 wt\% CRT mortar, d - 50 wt\% CRT mortar

The density of the glass containing hardened mortars (30 wt $\%, 40 \mathrm{wt} \%$, and $50 \mathrm{wt} \%$ ) presents an increase of $2.46 \mathrm{wt} \%, 3.64 \mathrm{wt} \%$, respectively $4.37 \mathrm{wt} \%$ as compared to the control mortar. The high mortar density values can be correlated with the high glass density due to its content in heavy oxides.

\section{Mortar porosity}

According to the size distribution of both aggregates, there are no relevant differences between the size of CRT waste and river sand. As such, the mortar compactness should be close. The pore distribution, illustrated by blue colour, is presented in Figure 7. An uniform distribution and small size pores are present in both type of mortars, the control one and CRT waste mortar, respectively. 


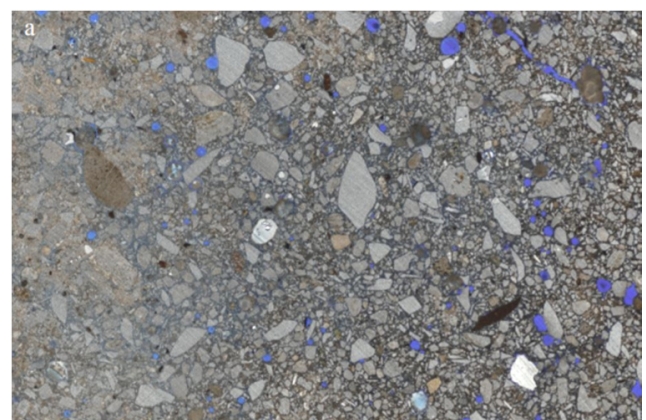

a

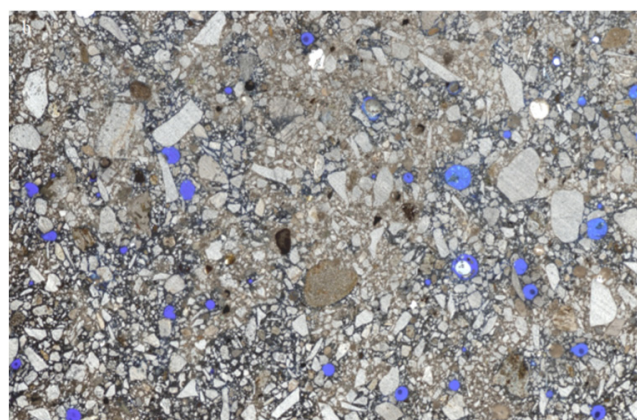

b

Figure 7. Porosity distribution of two studies samples: a - control mortar, b - 30 wt $\%$ CRT waste mortar

\section{Compressive strength}

Mechanical test reveals a better behaviour of the CRT glass containing mortars as compared to the control mortar (Figure 8). In each case, the glass has a positive influence on the mortar resistance. The compressive strength increases progressively with the decreasing of the river sand in favour of glass waste and with curing age.

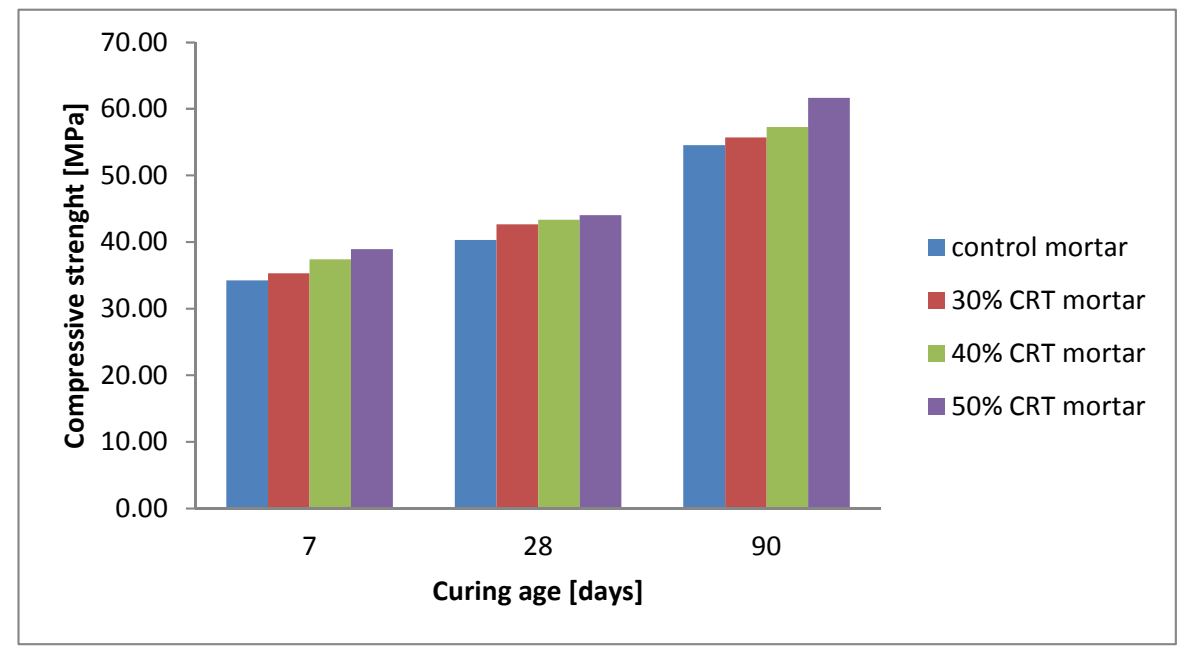

Figure 8. Compressive strength of studied mortars 
The mortars with $50 \mathrm{wt} \%$ CRT glass content show the highest compressive strength at 90 days, $61.69 \mathrm{MPa}$. This represents about $113 \%$ of control mortar strength at the same age. Romero [22] also demonstrates that the strength of mortars prepared with CRT glass waste in a lower amount (10 wt $\%, 20 \mathrm{wt} \%$ and up to $30 \mathrm{wt} \%$ ) surpass that of the control mortars. The improved behaviour could be explained by the glass's low water absorption that facilitates workability, and reduces drying shrinkage. Maschio [23] supports the fact that mortar samples prepared with glass prove a more rapid increase of strength as compared to the control mortar in long-term ageing.

Leaching test

After each period of maintaining the mortar samples in water, the resulting solutions were analysed by AAS apparatus with absorption limits between 0.1-100 ppm.

No evidence of $\mathrm{Pb}$ was detected in the solutions in this range.

\section{CONCLUSIONS}

This study investigates the characteristics of CRT glass cement mortars and possibility of encapsulating hazardous metal oxides from scrap monitors in these mortars as aggregates. CRT glass waste, traditional river sand, cement and water were mixed in order to obtain mortars.

The density of CRT waste mortars show higher values than control mortar as the aggregate is enriched in $\mathrm{PbO}$ and $\mathrm{BaO}$ glass.

The $\mathrm{pH}$ data fits into standard values for cement mortars. The AAS analysis made on the solutions consisting of mortar samples and deionised water indicates no dissolution of $\mathrm{Pb}$ in the 0.1-100 ppm range. It can be presumed that lead and barium oxides are well embedded by the cement matrix.

An uniform distribution and small size of the pores both in control as well as in CRT waste mortar are evidenced.

Compressive strength of studied mortars increases when a high percent of river sand aggregate is replaced. The best value is recorded by composition M4, in which CRT glass waste to river sand ratio is $1: 1$. In each case, the control mortars strength is exceeded by that of the CRT glass mortars.

Despite of their angular shape this type of aggregate makes a good bond with the cement matrix, fact proved by the compressive strength of mortar samples.

In conclusion, the CRT glass waste could be used as aggregates in cement mortar for replacing the river sand. 


\section{EXPERIMENTAL}

\section{Materials and methods}

\section{Materials}

In order to prepare the mortar samples, the cement, aggregate, and water as raw materials are necessary. A type II Cement A-LL 42.5 R was used for this study. Chemical composition of cement is presented in Table 1. Both traditional river sand and CRT glass waste as aggregates were used. River sand was sourced from the Cluj area and CRT glass was provided by Babeş-Bolyai University laboratory (scrap computers).

\section{Mortar samples preparation}

According to the standard EN-196-1-ASTM C305 three mortar prisms for each composition were prepared. The raw materials were mixed in a laboratory mixer. The mixture was immediately put into standard steel

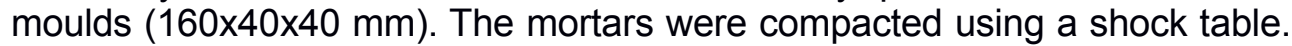
After 24 hours they were removed from the moulds and kept in $70 \mathrm{wt} \%$ humidity atmosphere for 7,28 and 90 days respectively.

\section{Tests methods}

Glass waste investigations

Alkali solubility was measured over a period of 7 days. $10 \mathrm{~g}$ of glass waste were weighted into a plastic jar with $100 \mathrm{ml}$ deionised water. The $\mathrm{pH}$ was determined with VERFAHREN pH -stat method (according to LAGA standard EW $98 \mathrm{P}$ ). The $\mathrm{pH}$ of the solution was measured every 5 minutes in the first 2 hours, then every 24 hours.

\section{Mortars investigations}

Compressive strength

Compressive strength of the hardened mortar was investigated after each setting time $(7,28,90$ days) using a CONTROLS Hydraulic Press 5036V2 according to Romanian SR EN 196-1.

\section{Chemical composition and surface phases}

Chemical composition and surface phases of the samples were studied with JEOL 640 Electron Microscope (Scanning Electron Microscopy SEM and Back Skattering Electron Microscope- BSE) coupled with Energy Dispersive Spectroscopy (EDS). The microstructure of prepared mortars was investigated at two different curing periods: 28 and 90 days. Presence of cracks in the images is common fact due to dehydration effects during sample preparation for SEM and BSE [21]. 


\section{Leaching test}

Lead solubility was determined at 14, 28 and 42 days. Pieces of mortars from mechanical tests are introduced in deionised water (1 part mortar in 2 parts water). After each period $10 \mathrm{ml}$ solution was collected for $\mathrm{Pb}$ testing with an AVANTA PM GBC Atomic Absorption Spectrometer.

\section{ACKNOWLEDGMENTS}

The authors wish to thank to Prof. Dr. Herbert Pöllmann and Dr. rer. nat. Ronny Kaden from Institute of Geosciences and Geography at Martin Luther University of Halle-Wittenberg, Germany and to Interdisciplinary Research Institute of Bio-Nano-Sciences of Babeş-Bolyai University Cluj Napoca.

\section{REFERENCES}

1. Ruixue Wang, Zhenming Xu, Waste Management, 34, 8, 2014, 1455

2. Qingbo $\mathrm{Xu}$, Guangming $\mathrm{Li}$, Wenzhi He, Juwen Huang, Xiang Shi, Waste Management, 32, 8, 2012, 1566.

3. J.R. Mueller, M. W. Boehm, C. Drummond, Waste Management, 32, 8, 2012, 1560.

4. Qingbo Xu, Mengjing Yu, A. Kendall, Wenzhi He, Guangming Li, J.M. Schoenung, Conservation and Recycling, 78, 9, 2013, 92.

5. L. Rocchetti, F. Beolchini, Waste Management, 34, 2, 2014, 468.

6. Ching-Hwa Lee, Chang-Tang Chang, Kuo-Shuh Fan, Tien-Chin Chang, Journal of Hazardous Materials, 114, 1-3, 18, 2004, 93

7. M. Leet Socolof, J.G. Overly, J.R. Geibig, Journal of Cleaner Production, 13, 13-14, 2005, 1281.

8. F. Méar, P. Yot, M. Cambon, M. Ribes, Waste Management, 26, 12, 2006, 1468.

9. İ. B. Topçu, M. Canbaz, Cement and Concrete Research, 34, 2, 2004, 267.

10. C. Meyer, S. Baxter, W. Jin, Proceedings of 4th materials engineering conference: materials for the new millennium. Reston, VA.: ASCE; 1996, 1388.

11. Ching-Hwa Lee, Chang-Tang Chang, Kuo-Shuh Fan, Tien-Chin Chang, Journal of Hazardous Materials, 114, 1-3, 18, 2004, 93.

12. C.S. Poon, Waste Management, 28, 9, 2008, 1499.

13. Fangfang Xie, Lili Liu, Jinhui Li, Environmental Sciences, 16, 2012, 585.

14. F. Andreola, L. Barbieri, A. Corradi, I. Lancellotti, Journal of the European Ceramic Society 27, 2007, 1623. 
15. F. Andreola, L. Barbieri, A. Corradi, I. Lancellotti, R. Falcone, S. Hreglich, Waste Management 27 (2), 2005, 183.

16. M. Dondi, G. Guarini, M. Raimondo, C. Zanelli, Waste Management, 29, 6, 2009, 1945.

17. J. Bartha, M. Gorea, STUDIA UBB CHEMIA LX, 4, 2015, 35.

18. Tung-Chai Ling, Chi-Sun Poon, Journal of Hazardous Materials, 192, 2, 30, 2011, 451.

19. Sarade Castro, Jorge de Brito, Journal of Cleaner Production, 41, 2, 2013, 7.

20. A.M. Oancea, M. Georgescu, A. Badanoiu, E. Matei, Romanian Journal of Materials, 2012, 42 (2), 152.

21. M. Schmidt, H. Poellmann, A. Egersdorfer, J. Goske, S. Winter, ICMA, 2011.

22. D. Romero, J. James, R. Mora, C.D. Hays, Waste Management, 33, 7, 2013, 1659.

23. S. Maschio, G. Tonello, E. Furlani, Journal of Waste Management, 2013, Article ID 102519, http://dx.doi.org/10.1155/2013/102519. 